\title{
INTEGRATING UAV PHOTOGRAMMETRY WITH TERRESTRIAL LASER SCANNING TO CHARACTERIZE MANAGED FOREST STANDS
}

\author{
Tuomas Yrttimaa ${ }^{1,2}$, Ninni Saarinen ${ }^{2,1}$, Ville Kankare ${ }^{1,2}$, Niko Viljanen ${ }^{3,4}$, Jari Hynynen ${ }^{5}$, Saija \\ Huuskonen ${ }^{5}$, Markus Holopainen ${ }^{2,3}$, Juha Hyyppä ${ }^{3}$, Eija Honkavaara ${ }^{3}$, Mikko Vastaranta ${ }^{1}$ \\ ${ }^{1}$ School of Forest Sciences, University of Eastern Finland, Joensuu, 80101, Finland \\ ${ }^{2}$ Department of Forest Sciences, University of Helsinki, Helsinki, 00014, Finland \\ ${ }^{3}$ Department of Remote Sensing and Photogrammetry, Finnish Geospatial Research Institute, National Land \\ Survey of Finland (NLS), Masala, 02431, Finland
}

${ }^{4}$ Department of Built Environment, School of Engineering, Aalto University, 02150 Espoo, Finland

${ }^{5}$ Natural Resources Institute Finland (Luke), Helsinki, 00790, Finland

Correspondence to: Tuomas Yrttimaa (tuomas.yrttimaa@uef.fi)

\begin{abstract}
Terrestrial laser scanning (TLS) provides detailed three-dimensional representation of the surrounding forest structure. However, due to close-range hemispherical scanning geometry the ability of TLS technique to comprehensively characterize the upper parts of forest canopy is often limited. To overcome challenges in upper canopy characterization, TLS point cloud were complemented with a point cloud acquired from above the canopy using UAV photogrammetry. The use UAV point cloud data was considered feasible especially in tree segmentation. With multi-sensoral approach $98.8 \%$ of all the 2102 Scots pine trees on the 27 sample plots were automatically detected. Root-mean-square-error (RMSE) in tree height estimates was $1.47 \mathrm{~m} \mathrm{(7.4 \% )} \mathrm{with}$ $0.33 \mathrm{~m}(1.7 \%)$ of underestimation. Plot-level forest inventory attributes were estimated with a relative RMSE less than $5.5 \%$ with the multi-sensoral approach. The results showed that in managed Scots pine forests the multi-scan TLS captures also the upper parts of the forest canopy and improvement in tree height measurement accuracy was obtained with the use of photogrammetric UAV point clouds. The RMSE in basal area-weighted mean height improved $34 \%$ (from $0.88 \mathrm{~m}$ to $0.58 \mathrm{~m}$ ) and the bias improved $40 \%$ (from $-0.75 \mathrm{~m}$ to $-0.45 \mathrm{~m}$ ) when UAV data was utilized. However, in this case the accuracy of TLS measurement was already high. In single-species, single-layer forest conditions, multi-sensoral approach generated benefits especially for forest height characterization. However, characterization of complex forest structures may benefit even more from point clouds that have been collected using sensors with different measurement geometries.
\end{abstract}

Keywords: Terrestrial Laser Scanning, Unmanned Aerial Vehicle, Point Cloud Processing

\section{INTRODUCTION}

Terrestrial laser scanning (TLS) provides detailed three-dimensional (3D) representation of the surrounding forest structure enabling automated characterization of trees and tree communities (Dassot et al. 2011, Newnham et al. 2015, Liang et al. 2016). Compared to the conventional forest inventory methods, the use of TLS point clouds enable non-destructive approaches to estimate stem profile and volume (Liang et al. 2012, Olofsson et al. 2014, Saarinen et al. 2017) and to characterize branching structure of trees (Raumonen et al. 2013, Pyörälä et al. 2018) which further improves the tree biomass modelling (Kankare et al. 2013, Calders et al. 2015). However, due to the close-range hemispherical scanning geometry, the ability of TLS technique to comprehensively characterize the upper parts of forest canopy is often limited (Schneider et al. 2019). Therefore, a several meters of error in TLS-based tree height estimates are common (Liang et al. 2018). Furthermore, errors in tree height estimates lead to erroneous stem volume and mean tree height estimates as well. To overcome the challenges with upper canopy characterization, TLS data could be complemented with a point cloud acquired from above the forest canopy (Wang et al. 2019). While better digitizing the upper canopy structure for more reliable tree height measurement, the multi-sensoral approach could also enable improved tree segmentation and more accurate point cloud-based estimates for plot-level forest inventory attributes. 
This is a non-peer reviewed preprint submitted to EarthArXiv

During the recent years, the use of unmanned aerial vehicles (UAV) has become a feasible option for smallscale forest monitoring (Wallace et al. 2016, Guerra-Hernández et al. 2018). Applying image processing techniques such as Structure from Motion approach for generating point clouds from overlapping images (Westoby et al. 2012), detailed 3D information on forest canopy structure can be acquired even using a consumer-grade UAV equipped with an RGB camera (Alonzo et al. 2018). With high temporal resolution in data acquisition, UAV photogrammetry is expected to suit for complementing multi-scan TLS data in forest monitoring applications. The objective of this study is to investigate the feasibility of combining photogrammetric UAV and TLS point clouds to improve the accuracy of detecting trees, measuring tree height and estimating plot-level forest inventory attributes on managed boreal forest stands.

\section{MATERIALS AND METHODS}

\section{Study materials}

The study materials consist of ground truth data and multi-sensoral point cloud data collected from 27 sample plots $\left(900-1200 \mathrm{~m}^{2}\right)$ located in two study sites in Southern Finland: Vilppula $\left(62^{\circ} 02^{\prime} \mathrm{N} 24^{\circ} 29^{\prime} \mathrm{E}\right)$ and Padasjoki $\left(61^{\circ} 21^{\prime} \mathrm{N} 25^{\circ} 06^{\prime} \mathrm{E}\right)$. The sample plots represent managed, even-aged Scots Pine (Pinus sylvestris L.) stands where the stand basal area ranges between $13.3 \mathrm{~m}^{2} / \mathrm{ha}$ and $43.3 \mathrm{~m}^{2} / \mathrm{ha}$ indicating large variation in stand density. The ground truth data comprises of 2102 Scots pine trees that were measured in the field using conventional field inventory methods. The plot-level forest inventory attributes were computed according to the procedure presented in Yrttimaa et al. (2019a).

The multi-sensoral point cloud data consists of TLS point clouds and photogrammetric UAV point clouds. The TLS data were collected using Faro Focus 3D phase-shift scanner with a multi-scan setup where hemispherical point clouds were acquired from eight scanning locations evenly distributed on each sample plot. Artificial reference targets were used to register and merge the individual point clouds together following the coregistration principle presented in e.g. Yrttimaa et al. (2019b). The UAV point clouds were acquired using Gryphon Dynamics quadcopter equipped with two Sony A7R II digital cameras mounted on $+15^{\circ}$ and $-15^{\circ}$ zenith angles. With a flying altitude of $140 \mathrm{~m}$ and flying speed of $5 \mathrm{~m} / \mathrm{s}$ a total of 1916 images were captured resulting of $1.6 \mathrm{~cm}$ ground sampling distance and $93 \%$ forward and $75 \%$ side overlaps. Eight ground control points (GCPs) were precisely measured for each study site. Photogrammetric processing was carried out using Agisoft Metashape Professional software (Agisoft 2019), following similar processing workflow as presented in Viljanen et al. (2018). In bundle adjustment the root-mean-square-errors (RMSE) of 0.29-1.75 cm were recorded for the X-, Y- and Z-coordinates. As a result, dense UAV point clouds were obtained with a reprojection error of $0.65-0.70$ pixels, point cloud resolution of $3.11-3.53 \mathrm{~cm} / \mathrm{pixel}$, and a point density of $804-$ 1030 points $/ \mathrm{m}^{2}$ depending on study site.

\section{Point cloud processing methods}

A modified version of the point cloud processing method presented in Yrttimaa et al. (2019a) was used in this study (Fig. 1). First, the TLS and UAV point clouds were normalized separately using LAStools software (Isenburg 2017) and a publicly available $2 \mathrm{~m} \times 2 \mathrm{~m}$ digital terrain model (DTM) with an expected vertical accuracy of $30 \mathrm{~cm}$ (National Land Survey of Finland). The normalized datasets were then registered and merged using 3D rigid transformation where the transformation matrix was computed based on the coordinates of tie points manually extracted for each sample plot.

Canopy height model (CHM) with a $20 \mathrm{~cm}$ resolution was generated from the UAV point cloud. Preliminary tree segmentation was then conducted using Variable Window Filter algorithm (Popescu \& Wynne 2004) to detect the tree top positions, and Marker-Controlled Watershed Segmentation (Meyer \& Beucher 1990) to eventually segment the tree crowns. The combined TLS-UAV-point cloud was then split according to the extracted crown segments, and cylindrical point cloud structures were searched and classified as stem points. Stem properties and sample plot metrics were finally estimated using the procedure presented in Yrttimaa et al. (2019a). 
This is a non-peer reviewed preprint submitted to EarthArXiv

\section{Accuracy evaluation}

Performance of the multi-sensoral approach to estimate the tree height and forest inventory attributes was evaluated by comparing the point cloud-derived estimates with the field-measured ones and by using bias and root-mean-square-error (RMSE) as accuracy measures. Tree detection accuracy was evaluated by computing how large a part of the field-measured trees were automatically detected from the point cloud.
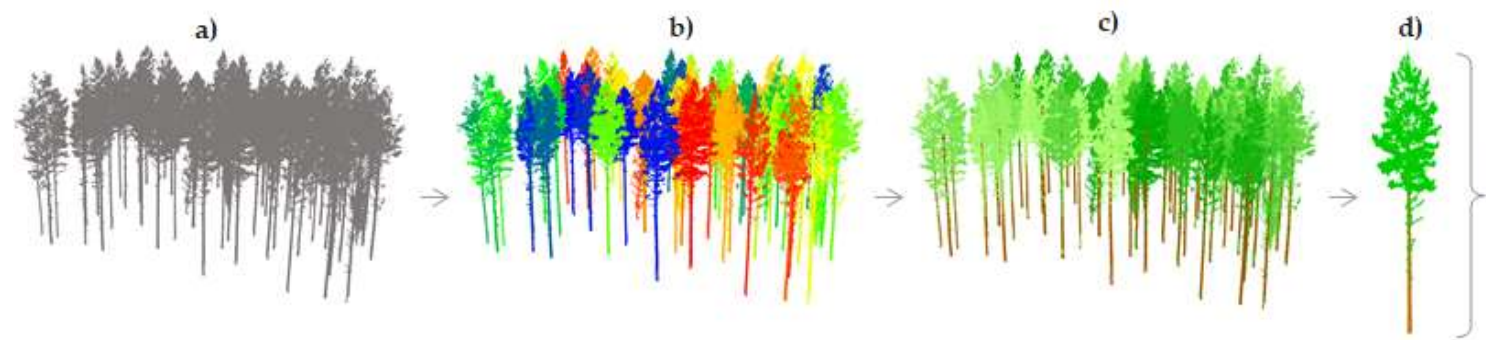

Stem properties: dbh, tree height, stem curve, volume, ...

Fig. 1. Outline of the point cloud processing method: (a) TLS and UAV point cloud registration, (b) tree segmentation, (c) point cloud classification, and (d) tree attribute extraction.

\section{RESULTS}

Out of the total number of 2102 Scots pine trees, $2076(98.8 \%)$ were automatically detected from the point clouds using the multi-sensoral approach. The stem volume of the detected trees accounted for $99.5 \%$ of the stem volume of all the trees. On average the tree height was underestimated by $0.33 \mathrm{~m} \mathrm{(1.7 \% )}$ and RMSE in the tree height measurements was $1.47 \mathrm{~m}(7.4 \%)$ with our multi-sensoral approach. The accuracy was slightly decreased when the measurements were only based on TLS data, as the tree height was underestimated by $0.65 \mathrm{~m}$ with an RMSE of $1.64 \mathrm{~m}$. Relative RMSEs of $<5.5 \%$ were recorded for all the forest inventory attributes when using the multi-sensoral approach (Table 1). Total volume was overestimated while the other attributes were underestimated. Erroneous tree height measurements seemed to compensate at the plot level as the basal area-weighted mean height was estimated more accurately than the individual tree heights. The use of TLS data only resulted in small but not relevant decrease in accuracy when estimating, $\mathrm{Hg}$ and $\mathrm{V}$.

Table 1. Accuracy of the estimated plot-level forest inventory attributes, such as basal area-weighted mean diameter $(\mathrm{Dg})$, basal area-weighted mean height $(\mathrm{Hg})$, stem number $(\mathrm{S})$, basal area $(\mathrm{G})$ and stem volume $(\mathrm{V})$ using multi-sensoral approach. Negative bias denotes underestimation.

\begin{tabular}{ccccc}
\hline & \multicolumn{2}{c}{ TLS + UAV } & \multicolumn{2}{c}{ TLS } \\
\hline Forest inventory attribute & Bias & RMSE & Bias & RMSE \\
\hline $\mathrm{Dg}(\mathrm{cm})$ & $-0.23(-1.0 \%)$ & $0.33(1.5 \%)$ & $-0.23(-1.0 \%)$ & $0.33(1.5 \%)$ \\
$\mathrm{Hg}(\mathrm{m})$ & $-0.45(-2.2 \%)$ & $0.58(2.8 \%)$ & $-0.75(-3.6 \%)$ & $0.88(4.3 \%)$ \\
$\mathrm{S}(\mathrm{n} / \mathrm{ha})$ & $-14.18(-2.0 \%)$ & $34.22(4.8 \%)$ & $-14.18(-2.0 \%)$ & $34.22(4.8 \%)$ \\
$\mathrm{G}\left(\mathrm{m}^{2} / \mathrm{ha}\right)$ & $-0.59(-2.5 \%)$ & $0.78(3.3 \%)$ & $-0.59(-2.5 \%)$ & $0.78(3.3 \%)$ \\
$\mathrm{V}\left(\mathrm{m}^{3} / \mathrm{ha}\right)$ & $4.97(2.1 \%)$ & $12.81(5.4 \%)$ & $0.82(0.4 \%)$ & $14.55(6.2 \%)$ \\
\hline
\end{tabular}

\section{CONCLUSIONS}

The use of point cloud-based forest inventory approach with multi-sensoral dataset consisting of photogrammetric UAV and multi-scan TLS point clouds succeeded in detecting almost all the trees on the sample plots while providing reliable estimates for the plot-level forest inventory attributes. The results showed that in managed Scots pine forests the multi-scan TLS captures also the upper parts of the forest canopy and improvement in tree height measurement accuracy was obtained with the use of photogrammetric UAV point clouds. The RMSE in basal area-weighted mean height improved $34 \%$ (from $0.88 \mathrm{~m}$ to $0.58 \mathrm{~m}$ ) and the bias improved $40 \%$ (from $-0.75 \mathrm{~m}$ to $-0.45 \mathrm{~m}$ ) when UAV data was utilized. However, in this case the accuracy of TLS measurement was already high. In single-species, single-layer forest conditions, multi-sensoral approach generated benefits especially for forest height characterization. However, characterization of complex forest structures may benefit even more from point clouds that have been collected using sensors with different measurement geometries. 
This is a non-peer reviewed preprint submitted to EarthArXiv

\section{REFERENCES}

Agisoft, 2019. Agisoft Metashape User Manual Professional Edition, Version 1.5. Available online: https://www.agisoft.com/pdf/metashape-pro_1_5_en.pdf (accessed on 7 January 2020).

Alonzo, M., Andersen, H. E., Morton, D., \& Cook, B. (2018). Quantifying boreal forest structure and composition using UAV structure from motion. Forests, 9(3), 119.

Calders, K., Newnham, G., Burt, A., Murphy, S., Raumonen, P., Herold, M., ... \& Kaasalainen, M. (2015). Nondestructive estimates of above- ground biomass using terrestrial laser scanning. Methods in Ecology and Evolution, 6(2), 198-208.

Dassot, M., Constant, T., \& Fournier, M. (2011). The use of terrestrial LiDAR technology in forest science: application fields, benefits and challenges. Annals of forest science, 68(5), 959-974.

Guerra-Hernández, J., Cosenza, D. N., Rodriguez, L. C. E., Silva, M., Tomé, M., Díaz-Varela, R. A., \& González-Ferreiro, E. (2018). Comparison of ALS-and UAV (SfM)-derived high-density point clouds for individual tree detection in Eucalyptus plantations. International journal of remote sensing, 39(15-16), 52115235.

Isenburg, M. LAStools-Efficient LiDAR Processing Software, (version 170511 academic); rapidlasso GmbH: Gilching, Germany. Available online: http://rapidlasso.com/LAStools (accessed on 19 December 2019).

Kankare, V., Holopainen, M., Vastaranta, M., Puttonen, E., Yu, X., Hyyppä, J., ... \& Alho, P. (2013). Individual tree biomass estimation using terrestrial laser scanning. ISPRS Journal of Photogrammetry and Remote Sensing, 75, 64-75.

Liang, X., Kankare, V., Hyyppä, J., Wang, Y., Kukko, A., Haggrén, H., ... \& Holopainen, M. (2016). Terrestrial laser scanning in forest inventories. ISPRS Journal of Photogrammetry and Remote Sensing, 115, 63-77.

Liang, X., Hyyppä, J., Kaartinen, H., Lehtomäki, M., Pyörälä, J., Pfeifer, N., ... \& Huang, H. (2018). International benchmarking of terrestrial laser scanning approaches for forest inventories. ISPRS journal of photogrammetry and remote sensing, 144, 137-179.

Meyer, F., \& Beucher, S. (1990). Morphological segmentation. Journal of visual communication and image representation, 1(1), 21-46.

Newnham, G. J., Armston, J. D., Calders, K., Disney, M. I., Lovell, J. L., Schaaf, C. B., ... \& Danson, F. M. (2015). Terrestrial laser scanning for plot-scale forest measurement. Current Forestry Reports, 1(4), 239251.

Olofsson, K., \& Holmgren, J. (2016). Single tree stem profile detection using terrestrial laser scanner data, flatness saliency features and curvature properties. Forests, 7(9), 207.

Popescu, S. C., \& Wynne, R. H. (2004). Seeing the trees in the forest. Photogrammetric Engineering \& Remote Sensing, 70(5), 589-604.

Pyörälä, J., Liang, X., Saarinen, N., Kankare, V., Wang, Y., Holopainen, M., ... \& Vastaranta, M. (2018). Assessing branching structure for biomass and wood quality estimation using terrestrial laser scanning point clouds. Canadian Journal of Remote Sensing, 44(5), 462-475. 
This is a non-peer reviewed preprint submitted to EarthArXiv

Raumonen, P., Kaasalainen, M., Åkerblom, M., Kaasalainen, S., Kaartinen, H., Vastaranta, M., ... \& Lewis, P. (2013). Fast automatic precision tree models from terrestrial laser scanner data. Remote Sensing, 5(2), 491-520.

Saarinen, N., Kankare, V., Vastaranta, M., Luoma, V., Pyörälä, J., Tanhuanpää, T., ... \& Yu, X. (2017). Feasibility of Terrestrial laser scanning for collecting stem volume information from single trees. ISPRS journal of photogrammetry and remote sensing, 123, 140-158.

Schneider, F. D., Kükenbrink, D., Schaepman, M. E., Schimel, D. S., \& Morsdorf, F. (2019). Quantifying 3D structure and occlusion in dense tropical and temperate forests using close-range LiDAR. Agricultural and forest meteorology, 268, 249-257.

Viljanen, N., Honkavaara, E., Näsi, R., Hakala, T., Niemeläinen, O., \& Kaivosoja, J. (2018). A novel machine learning method for estimating biomass of grass swards using a photogrammetric canopy height model, images and vegetation indices captured by a drone. Agriculture, 8(5), 70.

Wallace, L., Lucieer, A., Malenovský, Z., Turner, D., \& Vopěnka, P. (2016). Assessment of forest structure using two UAV techniques: A comparison of airborne laser scanning and structure from motion (SfM) point clouds. Forests, 7(3), 62.

Wang, Y., Lehtomäki, M., Liang, X., Pyörälä, J., Kukko, A., Jaakkola, A., ... \& Hyyppä, J. (2019). Is fieldmeasured tree height as reliable as believed-A comparison study of tree height estimates from field measurement, airborne laser scanning and terrestrial laser scanning in a boreal forest. ISPRS journal of photogrammetry and remote sensing, 147, 132-145.

Westoby, M. J., Brasington, J., Glasser, N. F., Hambrey, M. J., \& Reynolds, J. M. (2012). 'Structure-fromMotion' photogrammetry: A low-cost, effective tool for geoscience applications. Geomorphology, 179, 300314.

Yrttimaa, T., Saarinen, N., Kankare, V., Liang, X., Hyyppä, J., Holopainen, M., \& Vastaranta, M. (2019a). Investigating the Feasibility of Multi-Scan Terrestrial Laser Scanning to Characterize Tree Communities in Southern Boreal Forests. Remote Sensing, 11(12), 1423.

Yrttimaa, T., Saarinen, N., Luoma, V., Tanhuanpää, T., Kankare, V., Liang, X., ... \& Vastaranta, M. (2019b). Detecting and characterizing downed dead wood using terrestrial laser scanning. ISPRS journal of photogrammetry and remote sensing, 151, 76-90. 